\title{
PAISAGISMO NO PÁTIO ESCOLAR: A ARTE COMO INSTRUMENTO DE SENSIBILIZAÇÃO À EDUCAÇÃO AMBIENTAL ${ }^{1}$
}

\author{
Daniela Mengue Saft ${ }^{2}$, Paulo Edelvar Corrêa Peres ${ }^{3}$, Dionísio Link ${ }^{4}$, Toshio Nishijima ${ }^{5}$ \\ ${ }^{1}$ Este artigo é resultado da monografia do Curso de Especialização em educação Ambiental - \\ Centro de Ciências Rurais/UFSM. \\ ${ }^{2}$ Licenciada em Ciências Biológicas - Unisinos, Professora da rede Municipal de Sapiranga/RS, Pós- \\ graduada em Educação Ambiental - UFSM. \\ ${ }^{3}$ Orientador - Prof. Dr. Universidade Federal de Santa Maria - UFSM. \\ ${ }^{4}$ Revisor - Prof. Dr. Universidade Federal de Santa Maria - UFSM. \\ ${ }^{5}$ Revisor - Prof. Dr. Universidade Federal de Santa Maria - UFSM. \\ pecperes@yahoo.com, dlink@yahoo.com.br, toshionishijima@gmail.com
}

\section{RESUMO}

Atualmente, a maioria das escolas dispõe de pátios reduzidos, praticamente todos cimentados e sem atrativos. Esta proposta teve o objetivo de apresentar, discutir e criar alternativas interdisciplinares que promovessem interações entre meio ambiente, arte, estética e cultura como instrumentos de sensibilização para Educação Ambiental, através da reconstrução do pátio escolar. O trabalho foi realizado na EMEF Maria Ruth Raymundo, Sapiranga/RS. As atividades foram desenvolvidas em oito etapas entre abril e maio de 2010. Os resultados fomentaram discussões, reflexões e ações sobre temas ambientais e demonstraram a importância da arte na sensibilização das questões ambientais, fugindo da linguagem fatalista e ameaçadora.

Palavras-chave: meio ambiente, arte, interdisciplinaridade.

\section{ABSTRACT}

Most of the schools in Brazil have currently small schoolyards, generally cemented and unattractive. This proposal aimed to present, discuss and create alternatives that promote interdisciplinary interactions between environment, art, aesthetics and culture as tools to raise sensibility of Environmental Education, through the reconstruction of the schoolyard. The study was conducted at the school EMEF Maria Ruth Raymundo, Sapiranga/RS. The activities were conducted in eight stages between april and may of 2010. The results of this proposal have been positive, since they fostered discussion, reflection and action on environmental issues. It was 
evident the participation of art in awareness of environmental issues, fleeing the fatalistic and threatening language so commonly addressed in this subject.

Keywords: environment; art; interdisciplinarity.

\section{INTRODUÇÃO}

A Educação Ambiental, tema de inúmeros estudos, fóruns, palestras e conferências, tornouse obrigatória no âmbito escolar brasileiro sob forma de tema transversal sendo perceptível sua relevância e importância na formação de cidadãos conscientes.

A problemática ambiental é uma das principais preocupações e desafios da atualidade e segundo Serrano (2003), as iniciativas que a instituições de educação básica estão implementando em relação à Educação Ambiental buscam a formação de cidadãos conscientes e comprometidos com as principais preocupações ambientais.

Portanto, é inegável que a Educação Ambiental seja um assunto conhecido nas escolas, havendo uma extensa gama metodológica para o desenvolvimento deste tema. No entanto, o que se percebe é que fora das salas de aula, os alunos encontram um ambiente desolado. Atualmente, a maioria das escolas foi agraciada com salas e ambientes multifuncionais mas, no entanto, apresenta um pátio reduzido, praticamente todo cimentado e sem atrativos.

O espaço para a criança brincar livremente, socializar, ter contato com a natureza, praticar esportes e até poder ficar sozinha durante o recreio diminuiu drasticamente nos últimos anos (FEDRIZZI, 1999). Deste modo, promover a naturalização dos pátios escolares pode ser uma forma de manter o entusiasmo dos estudantes, criando uma relação entre o que se ensina e o que se aprende, tanto durante as aulas, como nos recreio, fazendo do pátio escolar um recurso educacional para alcançar diferentes objetivos, permitindo que o aprendizado se torne mais claro e real.

Além disso, a partir dele, pode-se adotar o exercício interdisciplinar na escola, envolvendo os temas transversais às diferentes disciplinas, promovendo a contextualização do conhecimento.

A prática pedagógica tradicional trata os acontecimentos da realidade social sob forma fragmentada e desvinculada das experiências significativas do educando. Há necessidade, portanto, de se trabalhar a abordagem contextualizada fundamentada no ponto de vista globalizado, buscando a operacionalização através do aprendizado da interdisciplinaridade (FERREIRA, 2008).

Atualmente, a tarefa do professor não é ministrar aulas compartimentadas e de uma única disciplina, mas sim, socializar conhecimentos. E a melhor maneira para que isso aconteça é através da interdisciplinaridade.

Segundo Fazenda (2002), "muitos dizem que fazem (projetos interdisciplinares), mas poucos os fazem de forma consciente." O objetivo dessa metodologia, em sua opinião, é "dar visibilidade e movimento ao talento escondido que existe em cada um de nós".

Portanto, a formação de professores deve orientar-se para contextos diferenciados e intrinsecamente interligados, para que estes assumam a função de intelectuais transformadores destinados a construir um saber ambiental (GIROUX, 2003). 
Para Santomé (1998):

(...) a conceitualização da interdisciplinaridade é uma questão do nosso século, embora devamos reconhecer que em época passadas houve algumas tentativas. (...) é possível que Platão, tenha sido um dos primeiros intelectuais a perceber a necessidade de uma ciência unificada, propondo que esta tarefa fosse desempenhada pela filosofia.

Desenvolver atividades socioambientais práticas e interdisciplinares, no âmbito formal, é um desafio para todos os professores e o fato de se trabalhar com diferentes áreas e recursos, garante-se a intencionalidade de possibilitar uma análise mais crítica do tema (GOUVÊA, 2006).

Assim, além de oferecer um espaço mais agradável, o pátio passa a ser algo mais do que um lugar para colocar as crianças durante o período em que elas não estão nas salas de aula (FEDRIZZI, 1999). A presença de elementos artísticos, estéticos, funcionais e pedagógicos desperta para a verdadeira Educação Ambiental e através de atividades práticas, prazerosas e interdisciplinares motivam a frequência às aulas, gera qualidade na educação e de vida.

Diante disso, a reconstrução do pátio escolar apresenta-se como um excelente temagerador, tornando-se um elemento capaz de desenvolver a interdisciplinaridade envolvendo Educação Ambiental e a Arte, conectando conceitos teóricos a práticos, auxiliando no processo de ensino-aprendizagem, constituindo uma estratégia para atingir diferentes temas transversais.

É dentro desse contexto que se situa a presente proposta, que teve como objetivo apresentar, discutir e criar alternativas interdisciplinares que promovam interações entre meio ambiente, arte, estética e cultura como instrumentos de sensibilização para Educação Ambiental, despertando, no ambiente escolar, o sentimento de pertencimento e responsabilidade com o meio, contribuindo para a consciência ambiental.

\subsection{A linguagem poética e a sensibilização estética na percepção e cognição ambiental}

Indiscutivelmente, o século XX foi marcado pelo agravamento da degradação dos recursos naturais, ocasionando o aumento dos problemas e desequilíbrios ambientais. Diante disso, um dos maiores desafios que enfrentamos atualmente é a mudança de mentalidade e comportamento do ser humano em relação as suas intervenções ambientais.

Atualmente, um movimento crescente é o da Arte Educação Ambiental, que promove a preservação ambiental, como uma ferramenta para reflexões e ações em relação às questões ambientais, nas diversas atmosferas (DIAZ-ROCHA, 1997).

Marin e Kasper (2009), afirmaram que:

a complexidade do ser humano se reflete nas diversas formas com que se relaciona com o mundo. As percepções construídas em suas vivências vão além da compreensão racional a respeito dos fenômenos, comportando um estrato pré-intelectual nutrido especialmente da sensibilidade estética, da imaginação e da criação poética.

Mas em 1977, as orientações da Conferência Intergovernamental em Educação Ambiental, de Tbilisi, já explicitavam a importância dos sentidos e da subjetividade para a compreensão da complexidade das relações humanas, sociais, políticas e com a natureza, destacando a relevância das atividades culturais e artísticas nas práticas da Educação Ambiental (Dias, 1998). Nesse sentido, Brandão (2003) salientou:

A possibilidade de conhecimento compartilhado, o desenvolvimento da capacidade de reflexão crítica e a efetiva contribuição da Arte no processo de culturação dos povos são 
importantes instrumentos no desenvolvimento de uma cultura social que favoreça uma mudança de atitudes, sob a perspectiva de compreensão das relações sistêmicas.

Assim se percebe a necessidade da formação integral do ser humano, que envolva não somente suas dimensões intelectivas, mas também sua emotividade e sua capacidade de imaginação e criatividade e, onde "a percepção estética possibilita a redescoberta da conaturalidade do humano com a natureza". (MARIN e KASPER, 2009).

Cada vez mais se mostra evidente a necessidade estética na vida cotidiana e como afirma Tristão (2005), nós sempre nos sentimos atraídos pelo belo e pelo natural e a exploração estética da natureza pode resgatar seu valor além da mera contemplação.

Pensando assim, Diaz-Rocha (2008) disse que além de tornar as pessoas mais sensíveis, as obras de arte criadas pelos expressam artisticamente ou esteticamente como eles veem o mundo.

Desta forma, a produção de conhecimento do educador ambiental a partir de metodologias baseadas nas linguagens poéticas e outras dimensões simbólicas são capazes de articular diferentes níveis de percepção da realidade e promover interações entre ecologia, arte, educação e cultura (SILVA e CATALÃO, 2008).

\subsection{Cresce arte e verde nos pátios escolares}

Tanto o tema arte, quanto pátios escolares são temas de projetos escolares, podendo ser encontrados em diferentes enfoques e abrangências. Este último ainda de maneira tímida, mas crescente nas propostas atuais.

Em se tratando de pátios escolares, Fedrizzi (1999), estudou e desenvolveu diferentes projetos na área e tem apresentado propostas pertinentes. Fedrizzi e Tomasini (2003), destacam a importância da melhoria dos pátios escolares para tornar a escola um local mais atrativo e aprazível, sendo a vegetação bem planejada capaz de agregar valor estético, melhorando as condições de conforto e servindo como valiosa ferramenta de apoio ao trabalho de Educação Ambiental.

A presença de vegetação e ambientes naturais no pátio escolar pode lembrar as pessoas de que elas fazem parte de um sistema delicado e que nesse ambiente podemos cultivar alimentos e aprender muito com isso (FEDRIZZI, 1997, apud FEDRIZZI E TOMASINI, 2003).

Neste contexto, percebe-se que os exemplos e as possibilidades relativos ao cultivo de alimentos nos pátios escolares são inúmeros, afinal, não há dúvida que as hortas escolares sejam um recurso que permite diferentes atividades e podem proporcionar um aprendizado prazeroso e inovador.

Exemplo disso, são os diferentes projetos desenvolvidos, desde uma abrangência nacional como o projeto "Educando com a Horta Escolar" realizado pelo Fundo Nacional de Desenvolvimento da Educação (FNDE)/Programa Nacional de Alimentação Escolar em parceria com a Organização das Nações Unidas para a Agricultura e Alimentação (FAO) e com o apoio do Ministério da Educação. Como projetos menos abrangentes, envolvendo escolas e comunidades, como é o caso de "Construção coletiva de uma horta escolar: repercussões entre alunos e participantes" (PETTER, 2004), "A horta escolar na educação ambiental e alimentar: experiência do Projeto Horta Viva nas escolas municipais de Florianópolis" (MORGADO, 2006) ou "Horta Escolar: Um Laboratório Vivo" (FERREIRA e CARDOSO, 2006), como tantos outros exemplos, inclusive internacionais, como é o caso do projeto "Growing art", desenvolvido em Toronto, no Canadá (INWOOD, 2006). 
Outro tema que envolve a reconstrução de pátios escolares é o plantio de árvores. 0 aumento da vegetação nas escolas pode ultrapassar o enfoque de apenas se ter mais verde no ambiente escolar, e sim, pode propiciar e desenvolver conhecimentos ecológicos e ser utilizado como prática no cuidado com o meio ambiente, reforçando a consciência ambiental (AVILA et al, 2009).

Além disso, Fedrizzi e Tomasini (2003) verificaram, em seu projeto realizado nas escolas de Porto Alegre/RS, que tanto alunos como professores tendem a associar os benefícios da vegetação no pátio escolar ao valor estético.

Fedrizzi (2006) destacou ainda que mesmo pequenas mudanças podem fazer diferença nos pátios escolares e que ao se projetá-lo, o aspecto tamanho não pode restringir ideias, pois há diferentes soluções e possibilidades.

Diante disso, parece que "plantar arte" nos pátios escolares pode ser uma saída para sensibilizar quanto à Educação Ambiental, melhorar o ambiente da escola e consequentemente auxiliar no aprendizado dos alunos, já que "o pensamento sistêmico, fundador do conhecimento ambiental, pode ser melhor aprendido a partir dessas novas janelas da alma: corpo e sensibilidade" (CATALÃO, 2005).

\section{METODOLOGIA}

A proposta foi realizada na Escola Municipal de Ensino Fundamental Maria Ruth Raymundo, em Sapiranga/RS. A escola possui $2777 \mathrm{~m}^{2}$ (Figura $1 \mathrm{~A}$ ), tendo $2424 \mathrm{~m}^{2}$ de área construída (87\%), onde se encontram 12 salas de aula, biblioteca, ginásio, auditório, laboratório de informática, sala multifuncional, sala de projetos, cozinha, refeitório e banheiros, além das dependências administrativas (secretaria e diretoria). O pátio, de aproximadamente $359 \mathrm{~m}^{2}$ é $95 \%$ cimentado (Figura 1B), possuindo apenas três árvores, poucos vasos de flores e uma pequena horta com chás praticamente abandonada.

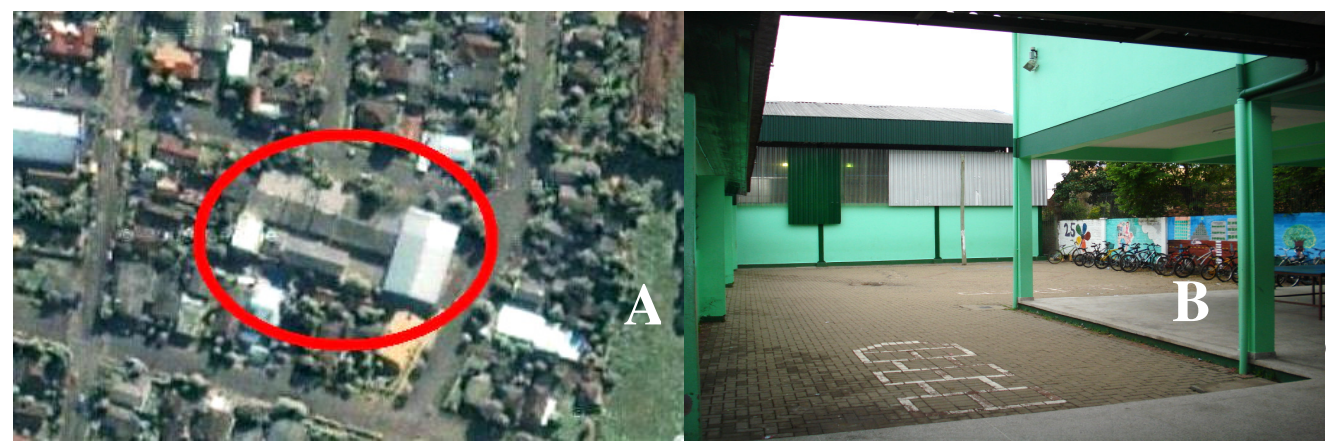

Figura 1 - Fotos do Pátio da Escola Municipal de Ensino Fundamental Maria Ruth Raymundo, em Sapiranga/RS.

Ao perceber a importância da interdisciplinaridade e a necessidade de sensibilizar para a Educação Ambiental e difundir a Arte, através da linguagem poética e da sensibilização estética, se propôs uma pesquisa-ação onde as percepções artísticas, estéticas e cognitivas contribuíssem para ampliação das percepções ambientais. 
Silva e Catalão (2008) entenderam que a Educação Ambiental pressupõe uma ação concreta de transformação do mundo, onde as coisas se transformam com a participação de diversos atores, sendo de extrema importância refletir e produzir conhecimento a partir das grandes contribuições da arte, percepção, educação estética, criatividade e sensibilidade. E salientam que a sensibilidade não pode mais ser considerada como mero sentimentalismo, vazio e inoperante, pois ela participa da complexa condição humana.

As atividades ocorreram entre os meses de abril e maio e foram distribuídas em oito etapas: apresentação da proposta aos professores, realização do questionário inicial entre os alunos, levantamento dos resultados, apresentação da proposta aos alunos das $8^{\text {as }}$ séries, construção e aplicação das atividades interdisciplinares, reconstrução do pátio escolar, realização do questionário final e levantamento e análise dos resultados.

O questionário inicial foi composto de oito questões (quatro questões abertas e quatro questões fechadas) e teve a finalidade de identificar o grau de satisfação dos alunos em relação às dependências e aparência da escola, bem como levantar sugestões para futuras melhorias. Os resultados deste primeiro questionário foram apresentados aos alunos das $8^{\text {as }}$ séries que fariam parte do grupo que realizaria as atividades práticas do projeto.

Segundo Catalão (2005), "a atitude interdisciplinar demanda um olhar sem viseiras e escuta sensível", então, tudo indica que além do interesse pelas questões ambientais e pelos processos criativos, o fator que reuniu cinco professoras da escola Maria Ruth Raymundo para aceitar a proposta e criar maneiras para aplicá-la foi a extrema capacidade de trabalho e crescimento coletivo.

Após discussões sobre o tema Educação Ambiental, linguagens artísticas e poéticas, construindo um engajamento entre questões ambientais e culturais, foram estabelecidas estratégias que dirigissem a ação interdisciplinar, numa perspectiva de educação integral. Cada professora assumiu um tema e uma ação para abordar em suas aulas, de forma que todas essas ações estivessem objetivos comuns que se interligassem.

A professora de Artes abordou artistas que trabalham com paisagismo, jardins verticais e o movimento land $\operatorname{art}^{6}$. Roberto Burle Marx, Gica Mesiara e Vik Munizforma alguns dos artistas estudados. Em relação à parte prática, os alunos construíram croquis do pátio, confeccionaram pufes, vasos de flores, miniaquários e um revisteiro com garrafas $\mathrm{PET}$, além de comedouros para pássaros com caixas de leite.

Nas aulas de Língua Portuguesa, os alunos estudaram haikai que é uma forma poética japonesa. A redação de haikai requer observação e prática, por isso, leva os estudantes-poetas a observarem a natureza, o que auxilia a perceberem seu pertencimento ao meio, favorece a crítica e, consequentemente, gera inquietações, como explica a professora titular desta disciplina na escola.

As aulas de Ensino Religioso serviram para refletir sobre mudanças. Questionamentos do tipo: "Será que estamos preparados para as mudanças?" "O que as mudanças podem fazer em nossas vidas?" "Que tipo de mudanças o mundo precisa?" foram feitas para despertar nos alunos a importância de estarmos prontos para as mudanças. Em relação ao projeto, essas mudanças precisavam ser apresentadas a toda escola e os demais alunos também deveriam estar preparados para recebê-las, afinal, iriam interferir na sua estada no pátio. Novas possibilidades surgiriam, mas novas regras também. Para isso, as turmas prepararam fôlderes, cartazes e apresentações para os

\footnotetext{
${ }^{6}$ Land Art ou Earth Art é um movimento artístico que emergiu nos Estados Unidos no fim da década de 60, no qual a paisagem e o trabalho artístico estão inextrincavelmente ligados é um tipo de arte onde o terreno natural é a própria galeria. São intervenções feitas no ambiente.
} 
alunos de toda a escola e os professores das demais turmas também foram convidados a abordarem o tema em suas aulas.

A professora de Matemática aproveitou o projeto para propôr aos alunos cálculos de equivalências. Após assisitirem apresentação em slides sobre equivalências em relação ao tamanho terrestre, os alunos receberam cálculos práticos relacionados ao projeto, assim os croquis dos quadros-vivos e das interferências no pátio receberam medidas proporcionais.

A reconstrução do pátio ocorreu na tarde do dia 25 de maio. Representantes das turmas de 8 a série se reuniram no turno oposto das suas aulas, munidos de seus trabalhos para a colocação destes no pátio.

Com a ajuda de pais voluntários e da professora coordenadora do projeto, os alunos fixaram os quadros, os pufes e os miniaquários nas paredes. Distribuíram os demais objetos de decoração avaliando as ideias feitas em aula com a elaboração dos croquis. Fedrizzi (2006) destaca a importância da organização espacial, uma vez que, a subdivisão dos pátios em áreas menores oferece múltiplo uso e permite o desenvolvimento de um maior número de atividades.

Por fim, com a intenção de se avaliar os resultados do projeto, aplicou-se um segundo questionário, seguindo os moldes do primeiro, ou seja, com uma amostragem de alunos (60). 0 questionário continha seis questões, onde três delas apresentavam questões abertas. As perguntas abordaram as mudanças do pátio e a satisfação dos alunos em relação a elas.

A análise dos dados e dos resultados colhidos ao longo e ao final do projeto, foi medida quantitativa e qualitativamente. Os dados quantitativos do projeto foram levantados sob escala de satisfação conforme resultados dos questionários I e II. Os depoimentos e reações através da identificação de palavras-chave, nos questionários I e II formaram a análise qualitativa.

\section{RESULTADOS E DISCUSSÃO}

A Educação Ambiental deve ter como base o pensamento crítico e inovador para promover a transformação da sociedade (DIAZ-ROCHA, 1997) e, para isso, é necessária uma vivência prática, descobrindo nosso impacto e nosso potencial de restauração (LEGAN, 2004).

Através do questionário inicial, os alunos puderam fazer uma leitura, avaliação e reflexão sobre seu entorno e a partir disso, sendo possível fazer um levantamento das suas percepções em relação às dependências da escola.

Conforme os dados levantados, a partir do questionário inicial, pode-se perceber tanto a boa relação dos alunos com os esportes como sua insatisfação frente ao pátio da escola.

Dos alunos pesquisados, 33\% deles preferiram o ginásio como a melhor dependência da escola. Entre as justificativas apareceram: o tamanho, a possibilidade de se fazer diferentes atividades e a melhor interação com os colegas.

O ginásio, sem dúvida, sempre desperta o interesse da maioria dos alunos porque está diretamente ligado às aulas de Educação Física, no entanto, questões relacionadas à estética também apareceram nas justificativas, como: "Lá é um lugar grande e bem enfeitado" (aluno 7 da 6a série - 14 anos) e "Eu gosto do ginásio porque é um lugar espaçoso, legal e bonito" (aluno da 5a série -10 anos).

\footnotetext{
${ }^{7}$ Como os participantes da pesquisa não foram identificados, aqui não serão diferenciados em relação ao gênero, sendo todos chamados de alunos.
} 
Assim como o Laboratório de Informática, sendo ele $28 \%$ das preferências, se deu pelo fato de ser um lugar agradável, limpo e bem estruturado: "É bem arejado, organizado, limpo e as atividades são bem legais" (aluno da 6ạ série - 11 anos) e "É climatizado e tem vários computadores, onde os alunos podem fazer atividades pedagógicas e se divertir com jogos e brincadeiras" (aluno da 8a série - 13 anos).

As demais dependências também tiveram a preferência relacionada à estética, organização e limpeza: "O auditório é o ambiente mais organizado da escola" (aluno da 7a série - 12 anos) e "A biblioteca é um lugar muito limpo, colorido e organizado" (aluno da 8a série - 13 anos).

O pátio da escola teve apenas 3\% das preferências e as justificativas ficaram relacionadas ao fato de ser um lugar para descontração e descanso "No pátio a gente pode se divertir e descansar um pouco" (aluno da 6a série - 11 anos).

O pátio atual da escola também apresenta insatisfação por parte dos alunos. Mais da metade (56\%), não aprova o pátio escolar.

Em outra questão abordada pelo questionário inicial, referente às melhorias do pátio escolar, o tamanho apresentou maior insatisfação e mais uma vez opções relacionadas à estética mostraram destaque.

O pátio da escola é realmente muito pequeno, uma vez que $87 \%$ da área total do educandário é construída e isso apareceu no questionário inicial como ponto crucial para melhoria deste ambiente, sendo $27 \%$ das reivindicações.

Também nesta questão, mais uma vez, o fator estético teve destaque, $25 \%$ dos alunos apontaram o fato da pintura necessitar de reparos como preferência de melhoria. Mas a falta de verde não ficou atrás: $21 \%$ dos alunos preferem um pátio mais verde, com árvores e flores e $100 \%$ dos alunos afirmaram que a presença de plantas na escola é importante. E quando perguntados o porquê desta importância, as respostas abrangeram temas como ar puro, clima e beleza: "Plantas são bonitas, coloridas e inspiram alegria" (aluno da 6a série - 14 anos).

Segundo estudo realizado por Fedrizzi e Tomasini (2003), verificou-se a tendência de professores e alunos em associarem, predominantemente, os benefícios da vegetação no pátio ao seu valor estético e que o contato com o verde reflete uma maior consciência sobre a importância e os benefícios das plantas no pátio da escola.

Marin (2006) aprofundou, quando disse que a percepção do ser humano em relação à natureza, a partir da experiência estética, "supera a rigidez e a vontade de domínio, devolvendoIhe a condição de co-naturalidade com seu meio."

Estes resultados comprovaram a necessidade de mudança do pátio escolar. O tamanho reduzido, a falta de verde natural e a falta de manutenção foram percebidos pelos alunos como pontos negativos, o que permitiu uma participação empolgante assim que foram convidados a participar da revitalização do pátio.

A reconstrução do pátio foi o ponto crucial da proposta, o momento mais aguardado. As tarefas foram trabalhosas e cansativas. No final da tarde todos já estavam exaustos. Porém, o trabalho em equipe e o resultado final, recompensaram tudo. Finalmente conseguimos revitalizar diversos ambientes (Figura 2): um muro, a entrada da sala dos projetos a parede e os pilares da área coberta, os nichos externos entre as salas, com pufes, comedouros e revisteiro, a parede do ginásio e da cozinha.

Passadas duas semanas da reconstrução do pátio, nova pesquisa de satisfação/percepção das mudanças foi realizada. Com este questionário pode-se perceber a importância e a diferença que fazem mudanças como esta. A respeito disso, $88 \%$ dos alunos responderam que precisávamos dessas mudanças há muito tempo e somente $2 \%$ pensam que elas não alteraram em nada 

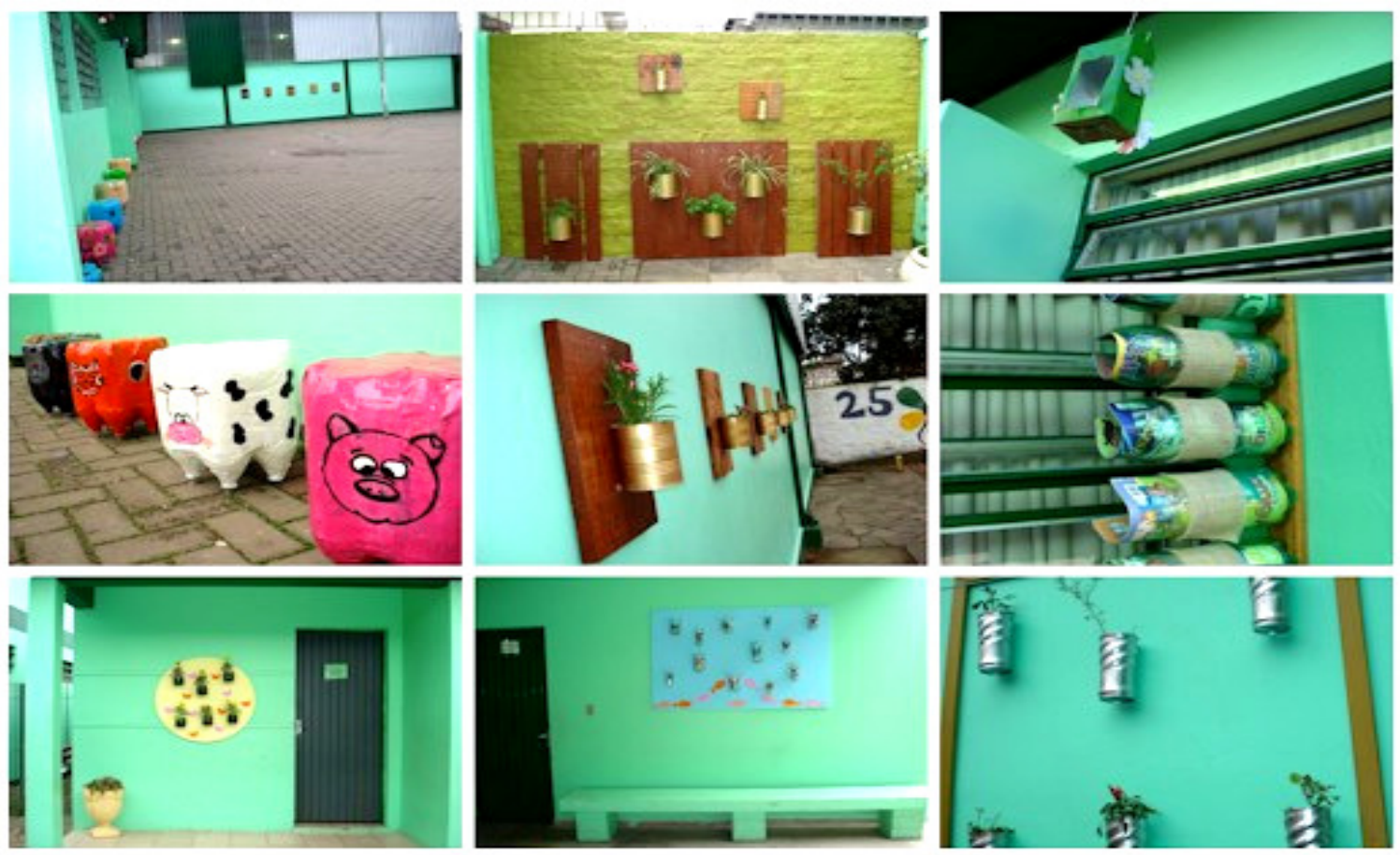

Figura 2: Ambientes revitalizados.

As mudanças foram qualificadas como boas por $96 \%$ dos alunos entrevistados e apenas $4 \%$ mostraram-se descontentes com as alterações, porque agora têm plantas para cuidar, justificaram a maioria deles.

As justificativas pelo contentamento estavam relacionadas com a estética, uma vez que $69 \%$ dos alunos disseram que gostaram das mudanças porque deixaram o pátio mais bonito, $24 \%$ salientaram a importância das plantas no pátio e $7 \%$ gostaram porque agora têm o que fazer no recreio

Também foi perguntado aos alunos qual das mudanças eles gostaram mais. As respostas foram relativamente equilibradas, havendo destaque apenas para a presença dos pufes (bancos), com $55 \%$ das escolhas. Em seguida vieram os miniaquários (18\%), quadros-vivos (15\%) e poemas (12\%).

Os alunos justificaram suas escolhas, mais uma vez, fazendo relação com a estética. Muitos destacaram a importância das mudanças para o embelezamento da escola: "Foi legal a ideia dos bancos, eles são bonitos e se tem onde sentar" (aluno da 8a série - 13 anos) e "O pátio ficou lindo. "Eu gostei dos quadros-vivos porque alegrou mais a escola" (aluno da 5a série - 11 anos).

Outra questão importante a ser avaliada era a disposição dos alunos no auxílio com as plantas. Afinal não basta dispor as flores nos vasos, elas precisam de cuidadas. Então foi perguntado aos alunos sobre seu interesse em ajudar na manutenção das plantas. A maioria dos alunos (92\%) se mostrou solícito em ajudar, justificando que elas precisam da nossa ajuda e destacando sua importância para o meio ambiente e para a beleza da escola: "Eu ajudarei porque 
as plantas fazem parte da natureza e deixam nossa escola mais bonita" (aluno da 8a série - 15 anos).

E finalmente foi perguntado se, mesmo com tais mudanças, o pátio da escola ainda necessitava de alterações. Diante desses questionamentos, $51 \%$ dos alunos responderam que sim, justificando que as mudanças foram positivas, mas que devem continuar. Eles solicitaram mais flores, mais cor, mais atividades no recreio e que as mudanças sejam constantes: "Ter sempre coisas novas, deixar a escola mais viva e cheia de cores" (aluno da 7a série - 14 anos).

Os professores também demonstraram encantamento com as mudanças e a eles foi solicitado que escrevessem um depoimento, avaliando a reconstrução do pátio.

A professora do 5o ano avaliou o projeto como sendo envolvente e empolgante, principalmente pelos resultados que está alcançando e acrescenta:

Os alunos estão empolgados com os trabalhos realizados e o nosso pátio está lindo, com muito mais vida e cor. E pensar que tudo foi feito a partir de material reciclável e ainda mais admirável. Podemos dizer que "tiramos água de pedra" trazendo vida para um pátio de concreto.

A coordenadora pedagógica também fez sua avaliação do projeto. Para ela, o projeto oportunizou grande conhecimento e reflexões para possíveis mudanças de comportamento e atitudes em nossos alunos, como também na comunidade escolar, que acompanhou de perto as transformações. E finaliza:

Parabenizo pela proposta, pois ficou visível o grande comprometimento e responsabilidade dos professores envolvidos em transmitir os valores quanto ao respeito à vida e a preservação ambiental. São com gestos como estes que nossos alunos, aos poucos, perceberão que é necessário mudarmos nossas atitudes para termos um mundo melhor.

Esses depoimentos corroboram o interesse e o comprometimento dos professores da Escola Maria Ruth Raymundo em desenvolver atividades significativas e enriquecedora a sua prática pedagógica, além de demonstrarem interesse e preocupação pelas questões ambit_ıdis.

\section{CONCLUSÕES}

A reconstrução do pátio escolar fomentou questionamentos e discussões no educandário. Professores e alunos percebem a importância dessas alterações e qualificam como sendo positivas e agradáveis.

As diferentes disciplinas puderam utilizar-se da sensibilidade estética e da linguagem poética a fim de estimular o cuidado e a preservação do meio ambiente, produzindo uma corrente de reações. Ou seja, as mudanças propostas para o pátio deixaram a escola mais verde e bonita, e isso permitiu um recreio mais agradável, que deixou felizes professores, alunos e comunidade escolar, que por sua vez perceberam a importância das plantas tanto para um ambiente mais saudável como esteticamente melhor.

Além disso, o projeto foi de grande relevância para transformar alguns conceitos estéticos nos alunos e professores. Questões como ocupação espacial, criação tridimensional, possibilidade de exploração de recursos reutilizáveis puderam ser debatidos, utilizados e transformados artisticamente.

Nesse sentido, emergiu a percepção que a construção de conhecimentos ecológicos necessita de vivências significantes, que suscitem reflexões e que sensibilize sem carregar um 
caráter fatalista. É preciso se utilizar de processos educativos abertos, que permitam as diferenças, aceitem a subjetividade e transforme hábitos.

\section{REFERÊNCIAS}

AVILA, A. L.; ARAÚJO, M.M.; NOGUERA, J.O.C.; GRINGS, V.T. Educação ambiental no Ensino Fundamental através da identificação e plantio de espécies arbóreas. Revista Eletrônica do mestrado em Educação Ambiental. FURG-RS. v. 22, janeiro a julho de 2009.

BRANDÃO, Cláudia Mariza Mattos. Arte e Educação Ambiental: as formas de um pensamento crítico-reflexivo. Educação Ambiental em Ação. n 3. 2003. Disponível em: http://www.revistaea.org/artigo.php?idartigo=112\&class=13 Acesso em 16 MAR 2010.

CATALÃO, V.L. A redescoberta do pertencimento à natureza por uma cultura da corporeidade. II Congresso Mundial de Transdisciplinaridade. Vila Velha/Vitória - ES. 2005. Disponível em:

www.cetrans.com.br/artigos/Vera Lessa Catalao.pdf Acesso em: 18 Mar. 2010.

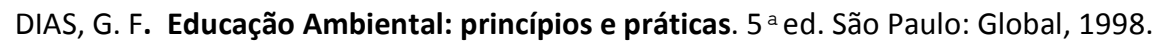

DIAZ-ROCHA, Paulo E. Arte Educação Ambiental como Práxis Política. In: Anais do IV Fórum de Educação Ambiental e I Encontro da Rede Brasileira de Educação Ambiental. Guarapari/ES, 1997.

DIAZ-ROCHA. Paulo E. Arte Educação Ambiental. O que é e para que serve? I Semana de Arte, Cultura \& Meio Ambiente da USP. SACMA - USP. São Paulo. 2008.

FAZENDA, I. C. A. Dicionário em Construção Interdisciplinaridade. Coletânea 2. Editora Cortez. São Paulo. 2002.

FEDRIZZI, B. Subsídios para projetos de pátios escolares públicos em Porto Alegre. Arqtexto - Revista Semestral do Departamento de Arquitetura do Propar - UFRGS. n 8. 2006.

FEDRIZZI, B. Paisagismo nos pátios escolares. UFRGS. Porto Alegre. 1999.

FEDRIZZI, B; TOMASINI, S. L. V. A vegetação no pátio escolar: um estudo para as condições das escolas municipais de Porto Alegre-RS. In: ENCONTRO NACIONAL SOBRE EDIFICAÇÕES E COMUNIDADES SUSTENTÁVEIS, São Carlos, 2003.

FERREIRA, C. A interdisciplinaridade da Educação Ambiental nas escolas: agente otimizador de novos processos educativos. Artigonal. 2008. Disponível em: http://www.artigonal.com/biologia-artigos/a-interdisciplinaridade-daeducacao-ambiental-nas-escolasagente-otimizador-de-novos-processos-educativos-482860.html Acesso em 01 de jul. 2009.

FERREIRA, S. C. M.; CARDOSO, Willany C. Horta Escolar: Um Laboratório Vivo. IV Encontro de Pesquisa em Educação da UFPI. Teresina, Piauí. 2006.

FUNDO NACIONAL DE DESENVOLVIMENTO DA EDUCAÇÃO (FNDE); ONU; MINISTÉRIO DA EDUCAÇÃO BRASIL. Projeto Educando com a Horta. 2008. Disponível em: http://www.educandocomahorta.org.br Acesso em: 15 maio. 2009

GIROUX, H. Atos impuros. Porto Alegre: Artes Médicas, 2003.

GOUVÊA, G. R. R. Rumos da formação de professores para a Educação Ambiental. Educar. Curitiba: Editora da UFPR, n. 27. 2006.

INWOOD, H. Growing Art in School Gardens. Green Teacher. Toronto. Canada. 2006. Disponível em https://www.highbeam.com/reg/reg1.aspx?origurl=/doc/1P3-1271837101.html\&full=yes. Acesso em 15 Mai. 2009. 
LEGAN, L. A escola sustentável - Eco-alfabetizando pelo meio ambiente. Editora Oficial. São Paulo, 2004.

MARIN, A. A. Educação Ambiental nos caminhos da sensibilidade estética. Inter-Ação: Rev. Fac. Educ. UFG, 31 (2): 277-290, jul./dez. 2006. Disponível em: http://www.revistas.ufg.br/index.php/interacao/article/viewArticle/1260 Acesso em 02 de ABR. 2010.

MARIN, A.A.; KASPER, K.M. A natureza e o lugar habitado como âmbitos da experiência estética: novos entendimentos da relação ser humano - ambiente. Educ. rev. [online]. 2009, vol.25, n.2, pp. 267-282. Disponível em: http://www.scielo.br/scielo.php?pid=S0102-6982009000200012\&script=sci abstract\&tlng=pt Acesso em 24 MAR 2010.

MORGADO, F.S.. A horta escolar na educação ambiental e alimentar: experiência do Projeto Horta Viva nas escolas municipais de Florianópolis. Universidade Federal de Santa Catarina. Florianópolis. 2006.

PETTER, C.M.B. Construção coletiva de uma horta escolar: repercussões entre alunos e participantes. Ponitifícia Universidade Católica do Rio Grande do Sul. Porto Alegre. 2004.

PPP. Projeto Político Pedagógico da Escola Municipal de Ensino Fundamental Maria Rurh Raymundo. Sapiranga, RS. 2010.

SANTOMÉ, J. T. Globalização e interdisciplinaridade: o currículo integrado. Trad. Claudia Schilling. Porto Alegre: Editora Artes Médicas, 1998.

SERRANO, C. M. L. Educação ambiental e consumerismo em unidades de ensino fundamental de Viçosa-MG. Dissertação (mestrado em Ciência Florestal) - Universidade Federal de Viçosa: UFV, 2003. 91p. Disponível em: http://www.ipef.br/servicos/teses/arquivos/serrano. Acesso em: 01 Maio 2009.

SILVA, R. G.; CATALÃO, V. L. O papel da sensibilidade e das linguagens poéticas nos processos formativos em educação ambiental: uma ciranda multicor. Dissertação de Mestrado em Educação, Universidade de Brasília UnB, 2008.

TRISTÃO. M. Tecendo os fios da educação ambiental: o subjetivo e o coletivo, o pensado e o vivido. Educação e Pesquisa, São Paulo, v. 31, n. 2, p. 251-264, maio/ago. 2005. 